\title{
REVIEW ARTICLE OPEN Predicting long-term corrosion of metal alloys in physical infrastructure
}

\author{
Robert E. Melchers (iD)
}

The conditions for initiation and the subsequent development of the severity of corrosion of metal alloys in the short term continue to be of research interest. However, for most physical infrastructure the critical issue often is the development and progression of corrosion under some level of oxygenated conditions, over several decades. In many cases this has significant implications for safety and for economic loss. Increasingly, asset management decision-making requires robust tools or models to predict the effect of corrosion, including loss, pit depth and crevice severity. The present capability in this area is reviewed and available models generally compared, including their degree of empiricism and their relationship to corrosion science fundamentals. It is argued that in addition to the role of material imperfections and corrosion products, the immediate physical environment adjacent to the metal alloy also can play a major role. These aspects are explored and some speculation made about required future research directions.

npj Materials Degradation (2019)3:4 ; https://doi.org/10.1038/s41529-018-0066-x

\section{INTRODUCTION}

For major infrastructure assets such as bridges, power generation facilities, pipelines, ships and offshore and coastal structures there is an increasing interest in delaying replacement and, if possible, expensive maintenance, as long as possible, consistent with societal expectations of adequate individual and societal safety and benefit. ${ }^{1}$ At one time these expectations were assumed met by the initial design and its compliance with existing design and safety rules, often as codified in national or, in some cases, industrial design standards. Implicitly it was assumed that a typical life, of say, 40-100 years for most infrastructure assets, would be achieved. However, increasingly it is found that such a priori assumptions are not always adequate and increasingly there are requirements to assess existing facilities for existing safety and adequate performance and, if possible, estimate their remaining life. A major limiting factor of such efforts is the availability of models for prediction of likely future deterioration. This includes models for predicting corrosion of steels and other alloys in aggressive environments such as marine and soil exposures. ${ }^{2}$ Consistent with the conventional approach for the design of major infrastructure, such models ideally should be based on fundamentals and calibrated to empirical data for actual infrastructure. ${ }^{3}$ They also should have a measure of their uncertainty or statistical variability, again to have them consistent with modern fundamentals for design of infrastructure, both minor and major. ${ }^{4}$ Traditional corrosion science has not really dealt with these issues, rightly being focussed mainly on developing improved understanding of the fundamental processes involved. Often this has been, and continues to be, limited mainly to corrosion initiation and short-term processes. On the other hand, traditional corrosion engineering consists of what might be termed 'empiricism', based largely on observations of actual performance in associated or similar exposure conditions, with only occasional detailed consideration of the corrosion science and other fundamental issues involved. This has worked well for cases that required only modest extrapolation in time. ${ }^{5}$ However, data for the time scales of interest to infrastructure (decades) is limited, and it is even more limited if understanding of the effect of various potential environmental influences is somehow likely to be important. This is particularly the case if protective coatings or cathodic or other protection systems cannot be relied upon for the whole of the intended life of the infrastructure, or if such systems have already become ineffective. In those circumstances understanding of fundamental corrosion processes over longer-term exposures becomes important. This is the issue discussed herein, with particular emphasis on structural steels in marine and in soil environments.

The next section provides a critical brief overview of a number of models presently proposed for corrosion loss as a function of exposure time. Such models usually focus on 'uniform' corrosion, even though it is well-known in practice that this is an idealisation of the actual corrosion phenomenon. Corrosion always occurs as a result of differences, in potential, metal composition, environment, etc. and hence is always non-uniform at some scale. ${ }^{6}$ In practice, however, the corrosion phenomenon has been divided into various phenomenological idealisations, including uniform, pitting, crevice, etc. Of these uniform corrosion and pitting having been given most research attention, although in practice other forms such as crevice corrosion are often more important. ${ }^{5}$

In the following, models for uniform corrosion are discussed first, particularly for extended exposures. This is followed by a broad review of modelling efforts for pitting corrosion, and in particular the depth and extend of pitting rather than the detailed physico-chemical processes inside pits. While in many practical situations crevice corrosion is important, little quantitative attention has been devoted to it. Crevice corrosion involves essentially the same corrosion processes as pitting but can be brought about by a variety of dissimilarity conditions, both within metal alloys and as caused by the corrosion environment through its present and possibly time-dependent physical, biological and

${ }^{1}$ Centre for Infrastructure Performance and Reliability, The University of Newcastle, Callaghan, Australia

Correspondence: Robert E. Melchers (rob.melchers@newcastle.edu.au)

Received: 15 August 2018 Accepted: 17 December 2018

Published online: 15 January 2019 
chemical characteristics. Although not addressed herein, in the context of predicting realistic likely future corrosion, the question naturally arises as to the usefulness and effectiveness of some of the techniques commonly used to accelerate corrosion processes.

\section{MODELS FOR CORROSION LOSS WITH TIME}

It appears that the first mathematical model ever proposed to describe the development of (uniform) corrosion was that developed for the atmospheric corrosion of copper by Tammann ${ }^{7}$ in 1923 although according to Pourbaix ${ }^{8}$ an empirical version of it was in use even earlier. That model has become known as the 'power-law' model. It expresses the (assumed uniform) corrosion loss $c(t)$ (usually expressed as an equivalent loss of metal, in $\mathrm{mm}$ or $\mu \mathrm{m}$ and also sometimes as mass loss per unit area) as a function of exposure period $t$ (typically in years) by:

$c(t)=A t^{B}+C$

where $A, B$ and $C$ are empirical constants (in the original formulation $C$ was not included). It is based on the notion that the rate of corrosion of a metal (alloy) is controlled by the rate of oxygen diffusion through the rust layers that build up on the corroding surface, and that this rate decreases as the rust layers build-up with increasing corrosion. It assumes the rust layers are uniform, and that corrosion also is uniform.

The mathematics for the model as originally presented were not perfect and were improved by Booth ${ }^{9}$ who also noted the anomaly that the model predicts an infinite (instantaneous) rate of corrosion at $t=0$. From both physical and electrochemical points of view this cannot be correct. An improvement can be made by allowing variability in the rate of build-up of corrosion product and a degree of loss, and also allowing a short, earlier, period of corrosion controlled essentially by the kinematics of the chemical reactions involved immediately after first exposure, without any influence of the build-up of corrosion products. Further, it was shown that some algebraic gymnastics and approximations are required to go from the diffusion mathematics to the power law as usually presented. ${ }^{10}$

For purely Fickian diffusion $B$ should be 0.5 and $C=0$. This is seldom found in calibrating Eq. (1) to field data, and values between $B=0.3-1.0$ (and sometimes even higher) are not uncommon, particularly for atmospheric corrosion where Eq. (1) continues to be much applied, not just for steels ${ }^{11,12}$ but also other metal alloys such as aluminium. ${ }^{13,14}$ Further, the power law has been extended to deal with atmospheric pollution ${ }^{15}$ and to allow for various weather and other influences, ${ }^{16,17}$ including salt and sulphur dioxide deposition rates, time of wetness and temperature $^{18}$ and metal composition. ${ }^{19}$

Although the power law is sometimes claimed to be a 'natural law' for corrosion, ${ }^{20}$ there are serious issues with it. The constants are highly sensitive to small changes in data or to additional data, or to a longer time period for data. Typically the correlation between data and model is of increasingly poorer quality with longer-term data sets. ${ }^{21-23}$ For example, Hou and Liang ${ }^{24}$ found that with $C=0$ (i.e. using the conventional power law Eq. (1)) the constants $A$ changed from 0.055 to 0.028 and $B$ from 1.89 to 0.68 when the data set was expanded from 0-8 years exposure to 16 years, that is, with the addition of just one extra set of data. Fundamentally, and for applications, this is not particularly satisfactory.

It is common practice for Eq. (1) to be presented as a log-log plot. This tends to camouflage data deviations from Eq. (1) and this is compounded by the use of curve-fitting criteria (such as $R^{2}$ ) based on the log-log data rather than the original data. ${ }^{25}$ Despite these deficiencies, Eq. (1) currently is still considered in some quarters as best practice. ${ }^{14,26}$
Alternatives to the power law have been proposed already over a long time, as reviewed by Evans. ${ }^{27}$ If instead of ionic control as in the power law, electronic transport considerations control, the socalled direct logarithmic law is obtained, and if a potential gradient drives the corrosion rate the inverse logarithmic law is obtained. There also was a proposal to model the development of early corrosion by considering ionic transportation governed by the movement through 'pores' within the metal structure, that is, along openings between grain boundaries and similar, leading to the notion of self-blocking of pores and the observed reduction in corrosion rate with time and the eventual almost cessation of corrosion, particularly for aluminium alloys. An asymptotic equation for this mechanism was proposed, ${ }^{27}$ although the concept is probably better modelled through the use of the tortuous paths at the grain boundaries forming the corrosion product layers. ${ }^{10} \mathrm{~A}$ development of the direct logarithmic model, popular in the Russian corrosion literature ${ }^{28}$ for longer-term exposures, is that based on the notion that the amount of corrosion loss $c(t)$ as a function of time $t$ is governed by the area of steel not yet covered by corrosion products, resulting in:

$c(t)=A\left(1-e^{B K_{0} t}\right)+K^{\prime} t$

where $A$ and $B$ are empirical constants, $K_{0}$ is the (empirical) initial corrosion rate and $K^{\prime} t$ is the asymptotic long term linear function. Assuming the non-linear part in Eq. (2) occurs relatively quickly and has little effect after a few years, a simplification of Eq. (2) is to consider the corrosion process comprised of two parts - and early power-law type behaviour followed by a longer-term linear function, of course continuous at the junction. ${ }^{29-31}$ This has been applied to atmospheric and also to marine corrosion (Fig. 1a).

A number of other (semi-) empirical models have been proposed, starting from different assumptions. Some of these attempted to allow for water temperature, dissolved oxygen and water velocity. ${ }^{32,33}$ Others have attempted to include corrosion in the atmosphere under dew conditions added to that occurring under rainfall conditions, both functions of environmental factors. ${ }^{34}$ Overall, these have not proved any better in fitting to longer-term data.

For representing the development of longer-term corrosion various models have been proposed, although it is seldom clear whether these are ultimately based on earlier work. Mostly they were presented as 'reasonable' representations, almost always empirical and calibrated to some observational data, almost all for atmospheric corrosion on land or for marine corrosion of ships. For ships interior corrosion is the main area of concern. Figure $1 a-d$ shows a summary of these 'practical' ship corrosion models. ${ }^{35-38}$ Some of these models include a period at the start to allow for loss of protective coatings or other corrosion inhibiting agents. This aspect is not considered herein as the processes involved are completely different from those involved in metal (alloy) corrosion. For the models in Fig. 1c, e the most surprising aspect is that they imply that, given sufficient exposure time, the instantaneous rate of corrosion declines to zero - in other words there is no further corrosion. This may be a reasonable conclusion for long-term aluminium corrosion but for steels there is little practical experience that would suggest this represents reality.

Models such as Fig. 1 c-e have been promoted in the engineering literature for assisting in assessing remaining structural life and for probability estimates of likely asset lifetimes. ${ }^{36}$ Typically these estimates use mean corrosion losses and corresponding variability, such as estimated standard deviations in a reliability framework. ${ }^{4}$ Both the means and the standard deviations (and sometimes the whole probability density functions) are estimated from the empirical data, typically obtained from data bases held by ship owners or classification societies. Such models also have been employed to present the 
a

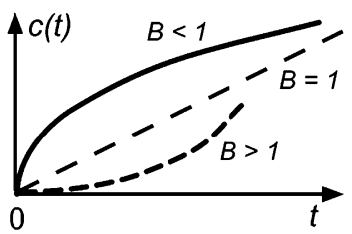

d

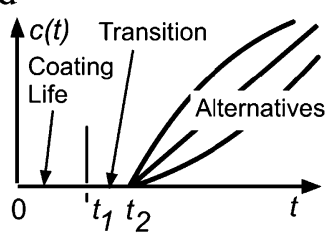

b

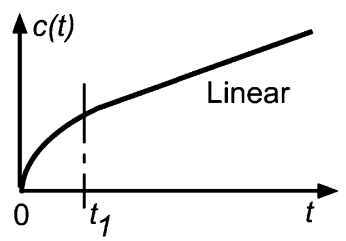

e

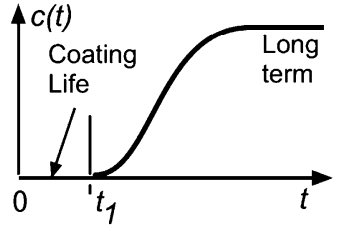

$\mathrm{c}$

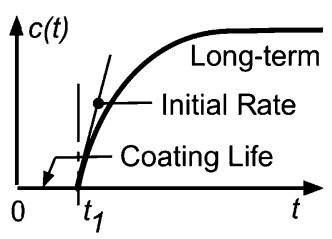

f

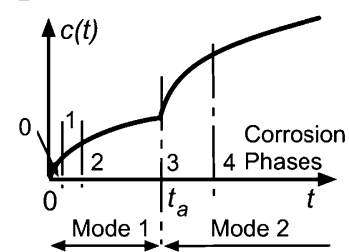

Fig. 1 Models proposed to represent development of corrosion loss with increased exposure time a Power Law. Case $B<1$ proposed and derived originally by Tammann (1923). Widely used for atmospheric corrosion. Empirical data may yield $B \geq 1$, b Non-linear smooth trend plus linear long-term trend. Used by various investigators for marine and for atmospheric corrosion, c Model proposed by Guedes Soares et al. that includes coating life and assumes that eventually the corrosion rate becomes zero, $\mathbf{d}$ Model proposed by Paik et al. that includes coating life and non-specific corrosion trends, generally similar to power law, e Model proposed by Qin and Cui that includes coating life and assumes that eventually the corrosion rate becomes zero, $\mathbf{f ~ B i - m o d a l , ~ m u l t i - p h a s e ~ m o d e l ~ p r o p o s e d ~ b y ~ M e l c h e r s ~ t h a t ~ m a c r o - m o d e l s ~ c o r r o s i o n ~ p r o c e s s e s ~}$ including a long-term linear trend

effect of factors with the potential to influence corrosion losses, again using similar data. As pointed out already many years ago, however, such data should be used with care. ${ }^{39}$ Typically the vessels will have undergone considerably different operational histories, including different trade routes, climatic conditions and loading and unloading routines, and as a result data aggregated over many different vessels do not constitute a homogeneous set. ${ }^{40}$ It is fundamental in statistics, and in probability theory, that data sets should be composed of independent homogeneous data (i.e. compare apples with apples, not apples with oranges). Failure to respect this basic requirement leads inevitably to very high deviations, and indeed this is typical of much ship corrosion data sets, with often the standard deviation being much larger than the mean value.

Overall the corrosion literature has very little data that can be considered homogeneous, or even data from which meaningful standard deviations can be estimated. Duplicate and sometimes triplicate samples are taken at any one sampling point, but this is insufficient to estimate variability. Ideally 30 or more samples are required, but even 9 can present an acceptable estimate. Indeed this has now been done for immersion corrosion ${ }^{41}$ and for pit depth $^{42}$ of mild steel in seawater but clearly much more effort is required to obtain sound estimates of variability for corrosion of other steels and of other metals and alloys.

A model more complex than those reviewed so far, but that has consistency with the original model by Tamman ${ }^{7}$ for short-term observations and the long-term linear aspect of the model in Fig. $1 \mathrm{~b}$ seen in longer term exposure data, ${ }^{30,31}$ and that also recognises that these two aspects (short- vs. long-term) involve different corrosion mechanisms is the bi-modal model. ${ }^{43,44}$ It has since been extensively elaborated to include the effect of water temperature, oxygen availability, water velocity ${ }^{45}$ and also the influence of waterborne nutrients on particularly the longer term corrosion losses. ${ }^{46,47}$ Recognition of these factors and their effect on the bi-modal model has permitted explanations to be offered for practical problems such as accelerated low water corrosion ${ }^{48}$ of steel sheet piling, ${ }^{49,50}$ channelling corrosion of water injection pipelines $^{51,52}$ and the severe pitting corrosion of mooring chains off the coast of West Africa and elsewhere. ${ }^{53}$ In addition, the bi-modal model also has been found to be consistent with data for the marine and other atmospheric corrosion of steels, ${ }^{54}$ corrosion of cast iron, ${ }^{55}$ copper-nickels $^{56}$ and aluminium, ${ }^{57}$ including for pitting corrosion. ${ }^{58}$ Moreover, the change in mode from 1 to 2 and the change in corrosion trend for these provides background for the wide variations in the constant $B$ in Eq. (1) for the power law (Fig. 1a) as well as the other models that use the power law (such as Fig. 1d). As noted above, the value for the constant $B$ in the power law depends much on the length of the record of the data considered. Overall, the overwhelming evidence ${ }^{45}$ is that the bimodal model of Fig. If provides the most robust representation of corrosion loss with time.

\section{PITTING CORROSION}

Localised corrosion

The models reviewed so far are based on the assumption that corrosion is uniform over the surface. This notion is reinforced by the frequent use of mass loss as a measure of corrosion. However, observations, even using a low-magnification optical microscope, show that uniformity is not a feature of actual corrosion, even for fresh water corrosion, ${ }^{59}$ and certainly not for slightly more aggressive environments such as for chloride or seawater environments. ${ }^{60}$ One traditional view is that 'pitting' can occur only for metals and alloys that have passive films ${ }^{61}$ and that only a run out on a potential-current density plot indicates a pitting event. However, at a more practical level pitting also has been associated for many years with alloys such as mild steel that form only (very) weak passive layers. ${ }^{60,62}$ This is more so for solutions containing chloride ions and other aggressive environments, and not only individual pits but clusters of localised corrosion with clearly identifiable features of pitting have been observed for mild and low alloy steels. ${ }^{60,63}$ As elaborated further below, this indicates that the environment itself is a key player in the overall behaviour, including that for pitting.

\section{Models for pit depth development}

In many cases the power law has been assumed to represent the growth of pit depth with time, ${ }^{13,64-66}$ and this is likely a reasonable model for very early pit growth (days, weeks), but there is now sufficient evidence that the pit growth behaviour is much more complex. First noted in passing by Gainer and Wallwork, ${ }^{67}$ pit depth develops very much along the lines modelled mathematically by Turnbull ${ }^{68}$ and Sharland and Tasker, ${ }^{69}$ that has the 
potential driving the increase in pit depth being exhausted as the pit depth increases. This leaves, eventually, only potential for sideways growth of pit depth. The electrochemical conditions are not straight-forward particularly where the pit mouth intersects with the original metal surface and any local corrosion products ${ }^{70}$ but the observations are clear enough - pits are not of simple shape (such as hemispherical), are seldom an isolated anode surrounded by a (near) circular cathodic region as was the classical view, ${ }^{6,27}$ and almost always occur in groups. ${ }^{63}$ Moreover, observations show that neighbouring pits may coalesce to form almost uniform depth depressions (sometimes noted by experimentalists as 'broad pits" ${ }^{\prime 1}$ that then provide a new surface for new pitting to occur. This leads to a stepped pattern of metal penetration, as observed in detail for mild steels, ${ }^{63}$ and also reported for cast iron $^{72}$ and most recently for 6060 Aluminium alloy exposed to seawater. ${ }^{73}$ These recent observations have been facilitated with the availability of surface scanners that permit the measurement of many pit depths, to an agreed base level, instead of the laborious process of measuring each pit depth independently to an uncertain base level.

Comparison of maximum pit depth development and the development of the depth of a small cohort of deepest pits (e.g. the 6 deepest $^{42}$ or the 12 deepest $^{31}$ shows that both tend to follow a non-linear function during the earlier exposures, consistent with the many earlier works, but that for longer exposures the depth trends become more like the bi-modal trends observed for mass loss. The crucial difference between these findings and earlier findings and assumptions are that the earlier works were based on rather sparse data for longer exposures, unable to discriminate the change in trend or were simply for data that spanned only a short period of time after first exposure. However, further reflection shows that for pit depth the bi-modal trend that appears to be observed largely is an artifice of the way the data is handled. Following on from the observations about the pitting process and the formation of broad pits that later show new pitting within them, it is clear that for maximum pit depth the trend must be a step-wise one. ${ }^{74}$ However, considering also other, less deep pits (such as the 6 deepest) means that the average pit depth becomes divorced from the clear step-wise changes in pit depth development. This departure from the trend for the deepest pit will increase as more and more pits are considered as constituting a cohort. In the limit, the average pit depth for a large number of pits is essentially a measure of mass loss and thus can be expected to follow a trend similar to mass loss. In summary, while the progression of maximum pit depth is very unlikely to follow a power law, it might be satisfactory for the average pit depth as a function of time, but of course only for relatively shortterm observations.

\section{Effect of the environment}

Pit initiation and to a lesser extent pit depth development, has largely been attributed to inhomogeneities of the metal surface. Such inhomogeneities might include, grain boundary defects, casting defects, differences in grain structure as might result from welding or heating, and non-metallic and other inclusions, such as for steels, manganese sulphide (MnS) inclusions, the latter implicated in pit initiation already many years ago. ${ }^{75}$ Mostly these observations were for corrosion studies carried out in stirred or agitated solutions, largely to obviate as much as possible diffusion of species, and that would otherwise slow down the rate of the reaction of interest. ${ }^{76}$ This acceleration technique might be acceptable for studies focussed on comparative corrosion rates in the very early stages of corrosion (phase 0 in Fig. $1 \mathrm{f}$ ) it does not reflect the conditions under which corrosion occurs once corrosion products (rusts) have built-up over the corroding surface. For temperate seawaters this occurs already within 2-3 months. ${ }^{77}$ The rusts that form tend to protect the surface underneath and hence the flow conditions at the metal interface are close to stagnant. This is important since already in 1908 it was demonstrated that under stagnant conditions the precise composition of the bulk solution was of little importance for the severity of corrosion. ${ }^{78}$ Moreover, for pitting the main anodic metal dissolution occurs within the pit, ${ }^{75}$ but of course only once the pit has developed and there are sufficient corrosion products over the pit to offer protection and keep the pit solution confined. ${ }^{70}$ The overall conclusion from these points is that careful attention must be paid as to whether the (artificial) corrosion studies in laboratory solutions do, or even can, replicate the conditions that occur in practice. Warnings about this abound, ${ }^{79}$ but they offer little guidance about translation from such tests to real conditions. In many cases, relevant practical information must rely ultimately on exposure tests under realistic conditions. $^{80}$

Not all corrosion occurs under conditions that can be modelled as equivalent to corrosion in liquids. The two most important practical examples are corrosion of metals or alloys in contact with soils (or particles) and corrosion of steel reinforcement bars in concrete. In both cases, papers simulating these cases with corrosion in the corresponding (or artificial) fluids abound, but in view of the observations by Burns and Salley ${ }^{81}$ these are unlikely to be sufficiently realistic. They noted, experimentally, that inert particles on lead sheet caused very localised corrosion under each particle. They deduced that because larger particles had a larger foot-print they would cause more localised corrosion but that there also was a limit and this appeared to be related to the availability of oxygen to the corroding regions. Surprisingly these findings, perhaps now rather obvious in view of what is known about pitting, have gone almost un-noticed in the studies focussed on the corrosion of steels and cast irons in various soils. It is sufficient to note that despite some 60 years since the hallmark study published by Romanoff ${ }^{82}$ little sense has been made of the data. ${ }^{83,84}$ Almost all effort has gone into artificial soil moisture studies, and attempts to relate soil moisture chemistry with corrosivity. ${ }^{85,86}$ In view of the above comments on solution chemistry in stagnant conditions, and the effect of local contact with particles, such studies are irrelevant. However, some sense can be made of the Romanoff data if it is recognised that the bimodal function applies also to corrosion in soil, for exposures up to at least 17 years, as recently demonstrated. ${ }^{87}$ One benefit of this recognition is that it has allowed a separation of the mechanics of corrosion involved in short-term exposures and conditions that pertain in the longer term. It has also allowed new interpretations of the available longer term data, such as that of Romanoff. ${ }^{82}$ This was done using the parameters of the model, the observation that the specimens are actually in back-filled soil rather than the original soil, and the recognition that corrosion initiates at soil void spaces (which hold water and oxygen) in contact with the metal. Longer term corrosion is thus dependent on the replenishment of both water and of oxygen, and thus depends on the effective permeability of the soil as well as its water-holding capacity. ${ }^{88,89}$ Fine soils such as sands cause little corrosion, whereas stiff lumpy clays, when used as back-fill, leave large voids and cause severe localised corrosion, including after many years exposure. ${ }^{90}$ These findings are entirely consistent with industry field observations.

\section{CREVICE CORROSION}

Crevice corrosion can arise from any contact between the metal (alloy) being considered and another object. This includes the same or other metals and alloys, mill scale, corrosion products, fouling and marine growth. It involves loss of metal ions from under the contact surface thereby creating a cavity that need have no relationship to conventional pitting except that the fundamental mechanism is much the same. ${ }^{75}$ Under aerated conditions such as typical in laboratory tests, the basic mechanism is known 
as differential aeration. More generally, however, like pitting corrosion, crevice corrosion can occur whenever there is a potential difference to drive the anodic process, and this includes under essentially anaerobic conditions. ${ }^{91}$ In the latter case there is anodic metal loss as before but it is associated with a different cathodic reaction. In crevice corrosion even more so than for pitting, the cathodic reaction occurs away from the anodic region, that is, remote from the contact region.

Crevice corrosion is probably the most under-rated mechanism in corrosion studies. For example, the extensive work on the initiation and early development of pitting of stainless steels in various pristine fluids is remarkable for the observations obtained, particularly that related to neighbouring pits ${ }^{92}$ (although for mild steels rather similar results were obtained already by Butler et al. ${ }^{60}$ However, in practical situations this behaviour is likely to be overshadowed almost completely when crevice corrosion is possible - in most cases this will be much more severe than any pitting over the metal surface. One common example is the crevice corrosion of stainless steels at lap joints and also for other steels at lap (and similar) joints. ${ }^{5}$ Such corrosion is considered severe because of the rapid increase in depth of the localised corrosion and its extent, and the often surprisingly short time in which these occur. In the same time period neighbouring and often extensive areas show only microscopic, spatially almost uniformly distributed, pits of similar maximum depth.

Another example is the severe corrosion that can occur in natural seawater - noting that contrary to artificial seawater (let alone $\mathrm{NaCl}$ solutions) natural seawater is inhabited by marine species, including bacteria and other microbiological species, as well as species causing macro-fouling. Through the medium of microscopic biofilms these attach quickly to the metal surface almost immediately on first immersion. ${ }^{93,94}$ Many studies investigating microbiological effects have been carried out under laboratory conditions, typically in artificial conditions with elevated nutrient levels, single microbiological species and closely controlled environments. There is no doubt that this has produced (and continues to produce) a wealth of new information, but also reinforcing the realisation with each new research advance that the micro- and macro-biological ecosystems are much more complex than earlier thought. The practical challenge is how to deal with this and the reality that the natural environment is much more complex and varied than so far modelled in laboratories. In cases like this, to make progress it is sometimes necessary to revert to simpler ways of considering the practical problem. Thus, for microbiologically influenced corrosion (MIC) of steel infrastructure in marine environments, some success has been achieved simply by considering the nutrients necessary for MIC to occur, and the input-output relationship(s) between nutrients and severity of corrosion. ${ }^{46,49,53,91}$ That work, almost entirely empirical, but with theoretical backing, has shown that in terms of steel corrosion mass loss the major effect of MIC lies in phases 3 and 4 in the bi-modal model (Fig. 1f). Only in these phases do anaerobic corrosion processes dominate ${ }^{43}$ and thus provide good support for anaerobic MIC activities. Even though the main effect of MIC is in the longer term, good indications of the likelihood of MIC affecting longer term corrosion can be obtained from relatively short-term (1-3 year) field observations. ${ }^{49}$

Comprehensive models for the longer term progression of crevice corrosion itself, as measured for example by its depth and its extent, and the various factors that influence these parameters, for example, the size and shape and aspect ratio of the original crevice, appear as yet unavailable. Moreover, the scientific work on crevice corrosion so far has concentrated on structural and corrosion resistant steels, although, based on the similarities in pitting corrosion mechanisms between steels, aluminium alloys and copper alloys, ${ }^{75,95}$ it is likely that very similar mechanisms hold for other alloys. Much potential remains for model development for crevice corrosion in the area of stainless and corrosion resistant steel and other alloys, including the copper nickels and the various grades of aluminium, noting that the latter are much less prone to MIC.

\section{CONCLUSION}

To date much of corrosion research has focussed on the conditions under which initiation of corrosion occurs, and the relatively short-term development of such corrosion, including pitting, and more recently on comparison of mechanics for different materials, such as corrosion resistant alloys, glasses and ceramics. ${ }^{96}$ These efforts are of much scientific interest and continue to produce many useful insights even though they are not always of direct use in practical applications. One continuing difficulty is relating such observations to the longer term behaviour of much interest for infrastructure applications, since it is well-established that extrapolation from laboratory studies to field conditions is fraught with difficulties. ${ }^{97}$ From a more applied perspective the focus, until recently, has been more on descriptive approaches, defining, if somewhat superficially, various forms of corrosion, for example, inter-granular corrosion, crevice corrosion, under-deposit corrosion, etc. and measuring their effect in defined situations, such as on coupons, for relatively short periods, such as 12 months. However, the possible links between the laboratory observations at small scale and the development of corrosion at larger scales, including over longer exposure periods of up to say 100 years and over larger surfaces, both relevant for infrastructure applications, and the connection to the specialised forms of corrosion observed in practice appears to have received relatively little attention. Nevertheless, as indicated herein, it has become increasingly clear that there are links between them and that these links are possibly best approached through mathematical (and sometimes probabilistic) modelling at a macro-scale. Field experience and detailed consideration of the exposure conditions in realistic, as distinct from laboratory, environments shows that in practical scenarios crevice corrosion often is the dominant feature for many metal alloys. It manifests itself in a variety of ways, ${ }^{5}$ but the fundamental mechanism can be recognised repeatedly - it is always localised dissolution by a mechanism usually referred to simply as differential aeration but which may result from any difference in potential over a local surface area. In most practical situations the longer term localised corrosion effect often has only a tenuous relationship to the metal grain structure itself. In many practical situations the resulting long-term corrosion effect is related to the bulk environment - such as natural seawater with marine micro-and macro-organisms including fouling, and natural soil conditions with a diversity of materials and textures in contact with the metal or alloy. It also can be expected to relate to the micro-environment, such as under and the corrosion products, noting the variability with depth of corrosion product layers that has been observed for longer term exposures. ${ }^{98}$ An immediate challenge is the better understanding and definition of the relationships between the micro-scale corrosion phenomena to macro-scales and to include the environmental effects. Provocatively, it could be considered that only then will what is largely empirical corrosion engineering have the chance to morph into corrosion engineering science.

Another practical challenge is how to confront and, ideally, obviate or ameliorate the crevice corrosion threat for any alloy, new or old. Perhaps something can be learnt from Burns and Salley ${ }^{81}$ who in about 1930 observed the localised corrosion immediately under inert spherical particles placed on lead sheet immersed in water. On the basis of their observations they argued that smaller grain sizes theoretically should produce less severe crevice corrosion under the particles, although there was a lower limit, presumably when corrosion becomes dominated by metal grain size and by metal imperfection effects. However, it does suggest that extremely small/fine particles are likely to produce fine-scale crevice corrosion over surfaces in what is essentially a 
form of uniform corrosion. In turn this suggests that when surfaces are required to be in contact they might be separated by one or more layers of very fine particles so as to induce localised crevice corrosion under the particles rather than crevice corrosion at a much greater scale such as has been noted as often resulting from the direct contact of larger areas of metal surfaces or contact between metal surface and, say, non-metals acting as crevice formers.

A third challenge relates to statistical variability. Practical corrosion scenarios almost always contain what might be called a degree of randomness in the factors involved, although in actual fact these are seldom completely random and more commonly are expressible through probabilistic descriptions. However, this is possible only once sufficient investigation of these factors has been carried out, both to establish the functional forms of the relationships and to allow calibration to 'real-world' data. Fundamentally the process is no different to that carried out in other physical science/engineering areas. For improved understanding, particularly of pitting and crevice corrosion phenomena, understanding of precisely the conditions at every point on a metal surface is unlikely, and statistic techniques would seem to be inevitable. For pit depth at least there is a long history of invoking statistical methods ${ }^{99}$ and also for exploring pit interactions ${ }^{72,100}$ but more generally for corrosion modelling much remains to be explored.

\section{ACKNOWLEDGEMENTS}

We acknowledges the support of the Australian Research Council under Discovery grant DP130104410.

\section{AUTHOR CONTRIBUTIONS}

Robert E. Melchers is the primary (and only) author of this work and is responsible for the content.

\section{ADDITIONAL INFORMATION}

Competing interests: The author declares no competing interests.

Publisher's note: Springer Nature remains neutral with regard to jurisdictional claims in published maps and institutional affiliations.

\section{REFERENCES}

1. Paik, J. K., Melchers, R. E. (eds). Condition Assessment of Aged Structures. (Woodhead, Cambridge, 2008).

2. Frangopol, D. M., Tsompanakis, Y. (eds). Maintenance and Safety of Aging Infrastructure. (CRC Press/Balkema, Leiden, 2014).

3. Melchers, R. E. The effect of corrosion on the structural reliability of steel offshore structures. Corros. Sci. 47, 2391-2410 (2005).

4. Melchers, R. E. \& Beck, A. Structural Reliability Analysis and Prediction. 3rd Edn, (John Wiley, Chichester, 2018).

5. Harro, H. M. \& Port, R. D. The Nalco guide to cooling water system failure analysis. (McGraw-Hill, New York, 1993).

6. Jones, D. A. Principles and Prevention Of Corrosion. 2nd Edn, (Prentice Hall, Upper Saddle River, 1996).

7. Tammann, G. Lehrbuch der Metallographie. 2nd Edn, (Leopold Voss, Leipzig, 1923).

8. Pourbaix, M. in Atmospheric Corrosion, (ed, Ailor W. H.) 107-122 (John Wiley, New York, 1982).

9. Booth, F. A note on the theory of surface diffusion reactions. Trans. Faraday Soc. 44, 796-801 (1948).

10. Melchers, R. E. Mathematical modelling of the diffusion controlled phase in marine immersion corrosion of mild steel. Corros. Sci. 45, 923-940 (2003).

11. Morcillo, M., Simancas, J. \& Feliu, S. in Atmospheric corrosion, ASTM STP 1239, (ed. Kirk, W. W. \& Lawson, H. H.) 195-214 (American Society for Testing and Materials, Philadelphia, 1995).

12. Tidblad, J., Mikailov, A. A. and Kucera, V. in Marine corrosion in tropical environments, STP 1399, (ed. Dean, S. W., Delgadillo, H.-D. \& Bushman, J. B.) 18-32 (Am. Soc. for Testing and Materials, West Conshohocken, 2000).
13. de la Fuente, D., Otero-Huerta, E. \& Morcillo, M. Studies of long-term weathering of aluminium in the atmosphere. Corros. Sci. 49, 3134-3148 (2007).

14. Alcántara, J. et al. Marine atmospheric corrosion of carbon steel: a review. Materials 10, 406 (2017).

15. Benarie, M. \& Lipfert, F. L. A general corrosion function in terms of atmospheric pollutant concentrations and rain pH. Atmos. Environ. 20, 1947-1958 (1986).

16. Feliu, S., Morcillo, A. \& Feliu, S. Jr. The prediction of atmospheric corrosion from meteorological and pollution parameters - 1. Corros. Sci. 34, 403-422 (1993).

17. Lyon, S. B., Wong, C. W. \& Ajiboye, P. in Atmospheric corrosion, STP 1239, (eds Kirk, W. W. \& Lawson, H. H.) 26-37 (American Society for Testing and Materials, Philadelphia, 1995).

18. Tidblad, J., Mikailov, A. A. \& Kucera, V. in Marine corrosion in tropical environments, STP 1399, (eds Dean, S. W., Delgadillo. H.-D. \& Bushman, J. B.) 18-32 (Am. Soc. for Testing and Materials, West Conshohocken, 2000).

19. Townsend, H. H. Atmospheric corrosion performance of quenched-and-tempered, high-strength weathering steel. Corrosion 56, 883-886 (2000).

20. Vera, R., Rosales, B. M. \& Tapia, C. Effect of the exposure angle in the corrosion rate of plain carbon steel in a marine environment. Corros. Sci. 45, 321-337 (2003).

21. Forgeson, B. W., Southwell, C. R. \& Alexander, A. L. Corrosion of metals in tropical environments - Part 3 - underwater corrosion of ten structural steels. Corrosion 16, 105t-114t (1960).

22. Schumacher, M. (Ed.). Seawater Corrosion Handbook. (Noyes Data Corporation, New Jersey, 1979).

23. Kreysa, G. \& Eckermann, R. Dechema Corrosion Handbook 11 (VCH Publishers, New York, 1992).

24. Hou, W. \& Liang, C. Atmospheric corrosion prediction of steels. Corrosion 60, 313-322 (2004).

25. Morcillo, M., Simancas, J. \& Feliu, S. in Atmospheric corrosion, STP 1239, (eds Kirk, W. W. \& Lawson, H. H.) 195-214 (Am. Soc. for Testing and Materials, Philadelphia, 1995).

26. Leygraf, J., Wallinder, I. O., Tidblad, J. \& Greadel, T. Atmospheric Corrosion (2nd edn) (Wiley, Hoboken, 2016).

27. Evans, U. R. The Corrosion And Oxidation Of Metals: Scientific Principles And Practical Applications. (Edward Arnold, London, 1960).

28. Mikhailovskii, Y. N., Strekalov, P. V. \& Agafonov, V. V. A model of atmospheric corrosion of metals allowing for meteorological and aerochemical characteristics. Prot. Met. 16, 396-323 (1980).

29. McCuen, R. H. \& Albrecht, P. in Applications of accelerated corrosion tests to service life prediction of materials, STP 1194 (Am. Soc. Testing Materials, Philadelphia (1994) 65-102.

30. Albrecht, P. \& Hall, T. T. Atmospheric corrosion resistance of structural steels. J. Mater. Civil Eng. 15, 2-24 (2003).

31. Southwell, C. R, Bultman, J. D. \& Hummer, C. W. in Seawater Corrosion Handbook (ed. M. Schumacher) 374-387 (Noyes Data Corp, Park Ridge, 1979).

32. Reinhart, F. M. \& Jenkins, J. F. Corrosion Of Materials In Surface Seawater After 12 And 18 Months Of Exposure. (Naval Civil Engg. Lab., Port Hueneme, 1972). Technical Note $\mathrm{N}-1213$.

33. Chernov, B. B. \& Ponomarenko, S. A. Physiochemical modelling of metal corrosion in seawater. Prot. Met. 27, 612-615 (1991).

34. Miyata, Y., Takekoshi, R. \& Takazawa, H. Techniques for estimating atmospheric corrosion rates of zinc in coastal areas. Corros. Eng. 38, 585-594 (1989).

35. Paik, J. K., Kim, S. K., Lee, S. \& Park, Y. E. A probabilistic corrosion rate estimation model for longitudinal strength members of bulk carriers. J. Ship Ocean Technol. 2, 58-70 (1998).

36. Guedes Soares, C. \& Garbatov, Y., in Safety and Reliability (ed. S. Lydersen, G. K. Hansen \& H. Sandtorv) 929-936 (Balkema, Leiden, NL, 1998).

37. Guedes-Soares, C., Garbatov, Y., Zayed, A. \& Wang, G. Non-linear corrosion model for immersed steel plates accounting for environmental factors. Trans., Soc. Nav. Archit. Mar. Eng. 111, 194-211 (2005).

38. Qin, S. \& Cui, W. Effect of corrosion models on the time-dependent reliability of steel plated elements. Mar. Struct. 15, 15-34 (2002).

39. Guedes-Soares, C. et al. Non-linear corrosion model for immersed steel plates accounting for environmental factors. Trans. Soc. Nav. Archit. Mar. Eng. 113, 306-329 (2006).

40. Gardiner, C. P. \& Melchers, R. E. Corrosion of mild steel by coal and iron ore. Corros. Sci. 44, 2665-2673 (2002).

41. Melchers, R. E. Modeling of marine immersion corrosion for mild and low alloy steels - Part 2: uncertainty estimation. Corrosion 59, 335-344 (2003).

42. Melchers, R. E. Pitting corrosion of mild steel in marine immersion environment 1: maximum pit depth. Corrosion 60, 824-836 (2004).

43. Melchers, R. E. Modeling of marine immersion corrosion for mild and low alloy steels - Part 1: phenomenological model. Corrosion 59, 319-334 (2003).

44. Melchers, R. E. \& Wells, P. A. Models for the anaerobic phases of marine immersion corrosion. Corros. Sci. 48, 1791-1811 (2006). 
45. Melchers, R. E. Progress in developing realistic corrosion models. Struct. Infrastruct. Eng. 14, 843-853 (2018).

46. Melchers, R. E. Long-term immersion corrosion of steels in seawaters with elevated nutrient concentration. Corros. Sci. 81, 110-116 (2014).

47. Melchers, R. E. Microbiological and abiotic processes in modelling longer-term marine corrosion of steel. Bioelectrochem 97, 89-96 (2014).

48. Beech, I. B. \& Campbell, S. A. Accelerated low water corrosion of carbon steel in the presence of a biofilm harbouring sulphate-reducing and sulphur-oxidising bacteria recovered from a marine sediment. Electrochim. Acta 54, 14-21 (2008).

49. Melchers, R. E. \& Jeffrey, R. Corrosion of long vertical steel strips in the marine tidal zone and implications for ALWC. Corros. Sci. 65, 26-36 (2012).

50. Melchers, R. E., Jeffrey, R. \& Usher, K. M. Localized corrosion of steel sheet piling. Corros. Sci. 79, 139-147 (2014).

51. Stipanicev, M. et al. Corrosion of carbon steel by bacteria from North Sea offshore seawater injection systems: laboratory investigation. Bioelectrochemistry 97, 76-88 (2014).

52. Comanescu, I., Melchers, R. E. \& Taxén, C. Corrosion and durability of offshore steel water injection pipelines. Ships Offshore Struct. 11, 424-437 (2016).

53. Fontaine, E., Potts, A. E., Kai-tung Ma, Arredondo, A. L. \& Melchers, R. E. SCORCH JIP: Examination and testing of severely-corroded mooring chains from West Africa, Offshore Technology Conference, Houston, 30 April-3 May, Paper OTC 23012, (Offshore Technology Conference, Houston, TX, 2012).

54. Melchers, R. E. The transition from marine immersion to coastal atmospheric corrosion for structural steels. Corrosion 63, 500-514 (2007).

55. Melchers, R. E. Long-term corrosion of cast irons and steel in marine and atmospheric environments. Corros. Sci. 68, 186-194 (2013).

56. Melchers, R. E. Bi-modal trends in the long-term corrosion of copper and copper alloys. Corros. Sci. 95, 51-61 (2015).

57. Melchers, R. E. Bi-modal trend in the long-term corrosion of aluminium alloys. Corros. Sci. 82, 239-247 (2014).

58. Melchers, R. E. Time dependent development of aluminium pitting corrosion. Adv. Mater. Sci. Eng. 2015, 10 (2015).

59. Melchers, R. E. \& Chernov, B. B. Corrosion loss of mild steel in high temperature hard freshwater. Corros. Sci. 52, 449-454 (2010).

60. Butler, G., Stretton, P. \& Beynon, J. G. Initiation and growth of pits on high-purity iron and its alloys with chromium and copper in neutral chloride solutions. Brit. Corros. J. 7, 168-173 (1972).

61. Burstein, G. T., Pistorius, P. C. \& Mattin, S. P. The nucleation and growth of corrosion pits on stainless steel. Corros. Sci. 35, 57-62 (1993).

62. Brasher, D. M. Stability of the oxide film on metals in relation to inhibition of corrosion. I. Mild steel in the presence of aggressive ions. Brit. Corros. J. 2, 95-103 (1967).

63. Jeffrey, R. \& Melchers, R. E. The changing topography of corroding mild steel surfaces in seawater. Corros.Sci. 49, 2270-2288 (2007)

64. Englehardt, G. \& MacDonald, D. D. Deterministic prediction of pit depth dis tribution. Corrosion 54, 469-479 (1998)

65. Velazquez, J. C., Caleyo, F., Valor, A. \& Hallen, J. M. Predictive model for pitting corrosion in buried oil and gas pipelines. Corrosion 65, 332-342 (2009).

66. Alamilla, J. L., Espinosa-Medina, M. A. \& Sosa, E. Modelling steel corrosion damage in soil environment. Corros. Sci. 51, 2628-2638 (2009).

67. Gainer, L. J. \& Wallwork, G. R. Effect of nonmetallic inclusions on the pitting of mild steel. Corrosion 35, 435-443 (1979).

68. Turnbull, A. A Review of modelling of pit propagation kinetics. Brit. Corros. J. 28 297-308 (1993).

69. Sharland, S. M. \& Tasker, P. W. A mathematical model of crevice and pitting corrosion - I. The physical model. Corros. Sci. 28, 603-620 (1998).

70. Galvele, J. R. Transport processes and the mechanism of pitting of metals. J. Electrochem. Soc. 123, 464-474 (1976).

71. Phull, B. S., Pikul, S. J. \& Kain, R. M. in Corrosion Testing in Natural Waters, STP 1300, 2nd Vol (eds R. M. Kain and W. T. Young) 34-73 (Am. Soc. for Testing and Materials, Philadelphia, 1997).

72. Soltani Asadi, Z. \& Melchers, R. E. Clustering of corrosion pit depths for buried cast iron pipes. Corros. Sci. 140, 92-98 (2018)

73. Liang, M. X., Melchers, R. E. \& Chaves, I. A. Complex pitting corrosion in long term immersed exposures of 6060 aluminium alloys in temperate natural seawater. Corrosion 74, 1272-1287 (2018).

74. Melchers, R. E. \& Ahammed, M. Maximum pit depth variability in water injection pipelines, In Proc. 28th International Ocean and Polar Engineering Conference (Sapporo, Japan, 2018) 289-294.

75. Wranglen, G. Pitting and sulphide inclusions in steel. Corros. Sci. 14, 331-349 (1974).

76. Levich, V. G. Physiochemical Hydrodynamics. (Prentice-Hall, Englewood Cliffs, 1962).

77. Melchers, R. E. \& Jeffrey, R. Influence of water velocity on marine corrosion of mild steel. Corrosion 60, 84-94 (2004).
78. Heyn, E. \& Bauer, O. Ueber den Angriff des Eisens durch Wasser und wässerige Losungen. Stahl. und Eisen 28, 1564-1573 (1908).

79. Kelly, R. G., Scully, J. R., Shoesmith, D. W. \& Buchheit, R. G. Electrochemical Techniques In Corrosion Science And Engineering. (Marcel Dekker, New York, 2002).

80. Stockert, L., Haas, M., Jeffrey, R. J. \& Melchers, R. E. Electrochemical measurements and short-term-in-situ exposure testing. In Proc. ACA Conference, Corrosion and Prevention 2012, (Australasian Corrosion Association, Melbourne, Paper No. 100, 2012).

81. Burns, M. \& Salley, D. J. Particle size as a factor in the corrosion of lead by soils. Ind. Eng. Chem. 22, 293-297 (1930).

82. Romanoff, M. Underground Corrosion. (US Government Printing Office, Washington, DC, 1957). (National Bureau of Standards Circular 579).

83. Ricker, R. E. Analysis of pipeline steel corrosion data from NBS (NIST) studies conducted between 1922-1940 and relevance to pipeline management. J. Res. Natl Inst. Stand. Technol. 115, (373-392 (2011).

84. Cole., I. S. \& Marney, D. The science of pipe corrosion: a review of the literature on the corrosion of ferrous metals in soils. Corros. Sci. 56, 5-16 (2012).

85. de Freitas Cunha Lins, V. \& Saliba, P. A. Corrosion resistance of API X52 carbon steel in soil environment. J. Mater. Res. Technol. 1, 161-166 (2012).

86. Doyle, G., Seica, M. V. \& Grabinsky, M. W. F. The role of soil in the external corrosion of cast iron water mains in Toronto, Canada. Can. Geotech. J. 40, 225-236 (2003).

87. Petersen, R. B. \& Melchers, R. E. Bi-modal trending for corrosion loss of steels buried in soils. Corros. Sci. 137, 194-203 (2018).

88. Gupta, K. \& Gupta, B. K. The critical soil moisture content in the underground corrosion of mild steel. Corros. Sci. 19, 171-178 (1979).

89. Akkouche, R. et al. Influence of soil moisture on the corrosion processes of carbon steel in artificial soil: active area and differential aeration cells. Electrochem. Acta 213, 698-708 (2016)

90. Melchers, R. E. \& Petersen, R. B. A reinterpretation of the Romanoff NBS data for corrosion of steels in soils. Corros. Eng. Sci. Technol. 53, 131-140 (2018).

91. Wang, X. \& Melchers, R. E. Long-term under deposit pitting corrosion of carbon steel pipelines. Ocean Eng. 133, 231-243 (2017).

92. Budiansky, N. B., Hudson, J. L. \& Scully, J. R. Origins of persistent interaction among localized corrosion sites on stainless steel. J. Electrochem. Soc. 151, B233-B243 (2004).

93. Little, B. J. \& Lee, J. Microbiologically Influenced Corrosion. (Wiley, New York, 2007).

94. Liengen, T., Feron, D., Basseguy, R., Beech, I. B. (eds.). Understanding Biocorrosion. (Woodhead, Cambridge, 2014). European Federation of Corrosion Publications, Number 66.

95. Wranglen, G. Introduction to Corrosion and Corrosion Protection. (Butler and Tanner, London, 1972).

96. Frankel, G. S. et al. A comparative review of the aqueous corrosion of glasses, crystalline ceramics and metals. npj Mater. Degrad. 2, 15 (2018).

97. Lee, J. S., Ray, R. I. \& Little, B. J. The influence of experimental conditions on the outcome of laboratory investigations using natural coastal seawaters. Corrosion 66, 1-6 (2010).

98. Refait, Ph, Grolleau, A.-M., Jeannin, M., François, E. \& Sabot, R. Localized corrosion of carbon steel in marine media: Galvanic coupling and heterogeneity of the corrosion product layer. Corros. Sci. 111, 583-595 (2016).

99. Melchers, R. E. A review of trends for corrosion loss and pit depth in longer-term exposures. Corros. Mater. Degrad. 1, 42-58 (2018)

100. Budiansky, N. D., Organ, L., Hudson, J. L. \& Scully, J. Detection of interactions among localized pitting sites on stainless steel using spatial statistics. J. Electrochem. Soc. 152, B152-B160 (2005).

Open Access This article is licensed under a Creative Commons Attribution 4.0 International License, which permits use, sharing, adaptation, distribution and reproduction in any medium or format, as long as you give appropriate credit to the original author(s) and the source, provide a link to the Creative Commons license, and indicate if changes were made. The images or other third party material in this article are included in the article's Creative Commons license, unless indicated otherwise in a credit line to the material. If material is not included in the article's Creative Commons license and your intended use is not permitted by statutory regulation or exceeds the permitted use, you will need to obtain permission directly from the copyright holder. To view a copy of this license, visit http://creativecommons. org/licenses/by/4.0/.

(c) The Author(s) 2019 